\title{
Estrutura populacional e desenvolvimento da fase esporofítica de Cyathea delgadii Sternb. (Cyatheaceae, Monilophyta) no sul do Brasil ${ }^{1}$
}

\author{
Jairo Lizandro Schmitt ${ }^{2,4}$ e Paulo Günter Windisch ${ }^{3}$
}

Recebido em 16/02/2006. Aceito em 26/01/2007

\begin{abstract}
RESUMO - (Estrutura populacional e desenvolvimento da fase esporofítica de Cyathea delgadii Sternb. (Cyatheaceae, Monilophyta) no sul do Brasil). Cyathea delgadii Sternb. é uma samambaia arborescente que ocorre em florestas primárias e secundárias da região nordeste até o sul do Brasil. O presente estudo discute a estrutura populacional e o desenvolvimento da fase esporofítica (crescimento do cáudice, produção de frondes, fenologia da produção de esporos) de $C$. delgadii, em floresta secundária, no Estado do Rio Grande do Sul, Brasil, baseado na observação de 41 plantas, durante 13 meses. A espécie apresentou padrão espacial agregado e uma freqüência expressivamente alta de indivíduos de menor altura, indicando um grande potencial de regeneração da população. O cáudice das plantas cresceu, em média, 4,65 $\mathrm{cm}^{2} \mathrm{ano}^{-1}$, sendo que as maiores taxas de crescimento foram registradas em plantas mais altas. As taxas de produção de frondes novas $\left(5,75\right.$ frondes ano $\left.{ }^{-1}\right)$ e de senescência $\left(4,92\right.$ frondes ano $\left.{ }^{-1}\right)$ similares evidenciaram uma capacidade de manter um número de frondes estável. Poucas plantas formaram frondes férteis, sendo que a produção e liberação dos esporos ocorreram assincronicamente.
\end{abstract}

Palavras-chave: pteridófita arborescente, ecologia, distribuição espacial, fenologia, taxa de crescimento

ABSTRACT - (Population structure and development of the sporophyte phase of Cyathea delgadii Sternb. (Cyatheaceae, Monilophyta) in Southern Brazil). Cyathea delgadii Sternb. is a tree fern that grows in primary and secondary forests from Norhteastern to Southern Brazil. This study discusses the population structure and development of the sporophytic phase (caudex growth, frond production, phenology of spore production) of $C$. delgadii in a secondary forest in the State of Rio Grande do Sul, Brazil, based on observations of 41 plants during a 13 month period. The species had an aggregated spatial distribution pattern and higher frequency of smaller individuals, indicating high potential for population regeneration. On average, the caudex of plants grew $4.65 \mathrm{~cm}_{\text {year }}{ }^{-1}$, and the highest growth rates were recorded for taller plants. The similar frond production rate $\left(5.75\right.$ fronds year $\left.^{-1}\right)$ and senescence rate $\left(4.92\right.$ fronds year $\left.^{-1}\right)$ reflect the capacity to maintain a stable number of fronds. Only a few plants formed fertile fronds, while spore production and liberation occur in an asynchronous pattern.

Key words: tree ferns, ecology, spatial distribution, phenology, growth rate

\section{Introdução}

Existem relativamente poucos estudos sobre a ecologia e desenvolvimento de Monilophytas arborescentes (Gomez 1983; Walker \& Aplet 1994; Bittner \& Breckle 1995; Schmitt \& Windisch 2005), sendo que essas plantas são um componente importante das florestas tropicais e subtropicais do mundo (Tryon \& Tryon 1982; Ash 1987; Arens \& Smith 1998).

Cyathea delgadii Sternb. é uma ciateácea de porte arborescente, que ocorre na Costa Rica, Panamá, ao redor da bacia Amazônica desde a Guiana Inglesa até a Bolívia, Paraguai e nas regiões Nordeste, CentroOeste, Sudeste e Sul do Brasil (Tryon 1976; Holttum \& Edwards 1983; Fernandes 2003). No Rio Grande do Sul, $C$. delgadii cresce em baixas altitudes (30 a $300 \mathrm{~m}$ ), nas florestas dos taludes dos morros da depressão central (Lorscheitter et al. 1999) e na encosta inferior do nordeste, ao longo de linhas de drenagem ou em vertentes rochosas úmidas, com cobertura rasa de solo arenoso. A espécie está desaparecendo em decorrência da fragmentação e

\footnotetext{
Parte da Tese de Doutorado do primeiro Autor. Programa de Pós-Graduação em Botânica, da Universidade Federal do Rio Grande do Sul

2 Centro Universitário FEEVALE, Instituto de Ciências da Saúde, Laboratório de Botânica, RS-239, 2755, Av. Dr. Maurício Cardoso, 510, 93352-250 Novo Hamburgo, RS, Brasil

3 Universidade do Vale do Rio dos Sinos, Av. Unisinos, 950, 93022-000 São Leopoldo, RS, Brasil

4 Autor para correspondência: jairols@feevale.br
} 
destruição dos habitats florestais, e atualmente, no Rio Grande do Sul, suas populações são reduzidas e muitas vezes desfalcadas de indivíduos jovens. Além disso, C. delgadii representa um alvo de exploração extrativista, sendo que seus cáudices são utilizados como substrato para cultivo de orquídeas, bem como mourãos de cerca, por apresentarem um fuste reto, relativamente liso e de alta dureza (Corrêa 1984).

A partir da década de 70, começaram os estudos pioneiros de auto-ecologia de samambaias arborescentes, destacando-se entre eles aqueles realizados por Conant (1976) com populações de Alsophila bryofila R.M. Tryon e Cyathea arborea (L.) Sm., em Porto Rico, e de Seiler (1981) com Alspohila salvinii Hook., no Bosque Montecristo, na América Central. Posteriormente, outros trabalhos do desenvolvimento de ciateáceas, enfatizando o crescimento do cáudice, a fenologia das frondes e/ou da produção de esporos foram realizados na Australásia (Ash 1987), Mesoamérica (Tanner 1983; Seiler 1984; Bittner e Breckle 1995), bem como na América do Sul (Ortega 1984; Arens \& Smith 1998; Arens \& Sánchez Baracaldo 2000; Arens 2001). Por outro lado, estudos apresentando aspectos sobre a estrutura populacional de Monilophytas arborescentes, de diversas regiões do mundo, também foram publicados por Tanner (1983), Young \& León (1989; 1991), Poulsen \& Nielsen (1995), Nicholson (1997) e Arens e Sánchez Baracaldo (1998). Dentre todos esses trabalhos, apenas o realizado por Bittner \& Breckle (1995) apresenta informações sobre Cyathea delgadii, relacionando habitat, crescimento do cáudice e idade das plantas, na Costa Rica.

No trópico e subtrópico úmido brasileiro, são escassos os estudos que discutem a estrutura populacional (Schmitt \& Windisch 2005) ou o desenvolvimento (Schmitt \& Windisch 2001; Schmitt \& Windisch 2003; Schmitt \& Windisch 2006) das ciateáceas, sendo que apenas Marcondes-Ferreira \& Felippe (1984), Randi \& Crozier (1991) e Randi \& Felippe (1988a,b,c,d,e,f) apresentaram informações sobre Cyathea delgadii, com especial atenção à germinação de esporos. Trabalhos de taxonomia (Holttum \& Edwards 1983), de florística (Klein 1979; Sylvestre \& Kurtz 1994) ou de botânica econômica (Hoehne 1930) contêm dados sucintos sobre C. delgadii. No entanto, conhecimentos sobre a estrutura populacional, taxas de crescimento do cáudice, das frondes e a fenologia da produção de esporos dessa espécie são praticamente inexistentes.
Diante desse contexto, o presente estudo tem como objetivos: (1) caracterizar a estrutura populacional, indicando o padrão de distribuição espacial e em classes de altura; (2) estabelecer dimensões e taxa de crescimento do cáudice; dimensões, taxas de produção, expansão e de senescência de frondes, correlacionando com fatores climáticos; (3) e determinar a fenologia da produção de esporos de Cyathea delgadii, crescendo em floresta secundária, no sul do Brasil.

\section{Material e métodos}

Área de estudo - O trabalho de campo foi conduzido no município de Novo Hamburgo (294ㄱ' S e 5058' W; s.n.m. 47 m), no Estado do Rio Grande do Sul, Brasil. A área de estudo é um remanescente florestal classificado como floresta estacional semidecidual (Teixeira et al. 1986), que ainda preserva algumas árvores originais, localizado ao longo de um córrego, que atravessa transversalmente o local. O estrato arbóreo forma um dossel contínuo e, no sub-bosque, encontra-se uma população de Cyathea delgadii. $\mathrm{O}$ solo é raso e arenoso, com pequenos afloramentos de arenito. As áreas adjacentes, atualmente, são utilizadas para fins agrícolas e turismo rural.

Nessa área, de acordo com a classificação climática de Köppen, o clima é do tipo Cfa (Moreno 1961). Segundo dados da estação meteorológica mais próxima, localizada no município de Campo Bom ( $29^{\circ} 41^{\prime}$ S e $51^{\circ} 03^{\prime} \mathrm{W}$; s.m.n. $25,8 \mathrm{~m}$ ), durante o ano de 2004, a temperatura média do mês mais frio (julho) foi de $12,9{ }^{\circ} \mathrm{C}$ e do mês mais quente (janeiro) foi de $25,1{ }^{\circ} \mathrm{C}$. A menor média das temperaturas mínimas foi de $7,8^{\circ} \mathrm{C}$ (julho) e a maior média das temperaturas máximas foi de $33,3{ }^{\circ} \mathrm{C}$ (janeiro). As precipitações mínima, máxima e anual foram, respectivamente, de 43,6 $\mathrm{mm}$ (dezembro), 211,9 $\mathrm{mm}$ (novembro) e $1341,6 \mathrm{~mm}$.

Descrição da espécie - Cyathea delgadii apresenta cáudice arborescente, ereto, de até aproximadamente $12 \mathrm{~m}$ de alt., com cicatrizes foliares planas e elípticas à rômbicas ao longo de toda a sua extensão. As frondes apresentam lâmina de até cerca de $3 \mathrm{~m}$ de compr., bipinado-pinatífidas, com ápice gradualmente reduzido. Os estípites apresentam espinhos ou são muricados ou inermes (Fernandes 2003).

Estrutura populacional - Foram demarcadas 38 parcelas de $10 \mathrm{~m}^{2}(2 \times 5 \mathrm{~m})$, arranjadas em duas 
transecções, com 20 e 18 parcelas cada, paralelas ao longo do córrego. Em janeiro/2004, foi realizada a contagem de todos indivíduos e registrada a altura dos cáudices vivos de Cyathea delgadii, presentes nas parcelas. As plantas não-férteis foram consideradas jovens e as plantas férteis adultas. Os indivíduos amostrados foram distribuídos em classes de tamanho, empregando intervalos de altura adotados por Tanner (1983) e Schmitt \& Windisch (2005): 0 a 0,8 m (Classe 1), >0,8 a 1,6 m (Classe 2), >1,6 a 2,4 m (Classe 3), >2,4 a 3,2 m (Classe 4), >3,2 a 4,0 m (Classe 5), $>4,0$ a 4,8 $\mathrm{m}$ (Classe 6), >4,8 a 5,6 m (Classe 7) e > 5,6 a $6,4 \mathrm{~m}$ (Classe 8). A densidade da população correspondeu ao número médio de indivíduos por 10 $\mathrm{m}^{2}$, bem como a uma estimativa por ha. $\mathrm{O}$ índice de Morisita (IM) e a razão (R) variância/média (Krebs 1989) foram utilizados para determinar o padrão de distribuição espacial da espécie. A significância estatística foi constatada através do teste de QuiQuadrado $\left(\mathrm{F}^{2}\right)$ para um nível de significância de 5\%. Os valores de IM e $\mathrm{R}$ menores que 1,0 indicam distribuição uniforme, iguais a 1,0 distribuição aleatória e maiores que 1,0 distribuição agrupada.

Fenologia - Em janeiro/2004 foi iniciado o período de acompanhamento mensal do desenvolvimento de 41 espécimes de Cyathea delgadii, que se estendeu até janeiro/2005. Na área de estudo, excluíram-se da amostra apenas os indivíduos em que não foi possível alcançar, com segurança, o ápice do seu cáudice para a coleta de dados. Os espécimes foram marcados utilizando-se estacas de madeira, com placas de alumínio numeradas, afixadas no substrato próximo ao seu cáudice. A altura das plantas foi mensurada do ápice do cáudice até o nível do solo, em janeiro/2004, e posteriormente, a um intervalo de 12 meses, para determinar a taxa de crescimento do cáudice. O número de báculos, frondes maduras (totalmente expandida com pinas verdes) e senescentes (com todas pinas secas ou somente bases de estípites) foram contados mensalmente, a fim de se determinar taxas de produção e de senescência de frondes. Báculos jovens foram marcados utilizando-se argolas de plástico e o seu desenvolvimento foi acompanhado para se determinar taxas de expansão de frondes. Foi registrado o comprimento do estípite, da lâmina e total dessas frondes recém expandidas. As frondes completamente senescidas, que eventualmente não se desprendiam do cáudice foram removidas, a cada mês, para evitar que não fossem reconsideradas na taxa de senescência do mês seguinte. Foi registrado o número de frondes férteis, o período em que havia esporângios imaturos, completamente cerrados, liberando esporos ou com a maioria dos esporos já liberados. Foi aplicado teste de correlação de postos de Spearman para verificar as relações entre: dimensões da fronde, produção e senescência foliar com altura das plantas; produção e senescência de frondes com precipitação mensal; média de frondes maduras e férteis com temperatura. $\mathrm{O}$ teste de t para amostras dependentes foi utilizado na comparação das médias de frondes maduras de janeiro de 2004 com as de janeiro de 2005 para verificar se o número de frondes se manteve estável, durante o período estudado (Vieira 1980; Zar 1999).

\section{Resultados}

Estrutura populacional - Na população estudada foram amostrados um total de 44 indivíduos, sendo 36 deles jovens (não-férteis) e oito adultos (férteis), em $380 \mathrm{~m}^{2}$ de área, distribuídos em oito classes de altura. O maior cáudice registrado foi de $6 \mathrm{~m}$ e o menor de $7 \mathrm{~cm}$. A classe de menor altura (classe 1) incluiu a grande maioria dos indivíduos jovens. Nenhum indivíduo foi incluído na classe 7. As demais classes apresentaram no máximo quatro espécimes. Plantas adultas foram registradas apenas a partir da classe 3 (Fig. 1), sendo que suas alturas mínima, máxima e média foram, respectivamente, de 1,7 m, $6 \mathrm{~m}$ e 3,65 $( \pm 1,24) \mathrm{m}$. Para a população de Cyathea delgadii foi estimada a ocorrência de 115 indivíduos.ha ${ }^{-1}$, sendo que a densidade observada na área foi de $1,15( \pm 2,18)$ indivíduos. $10 \mathrm{~m}^{-2}$. No máximo foram registrados 10

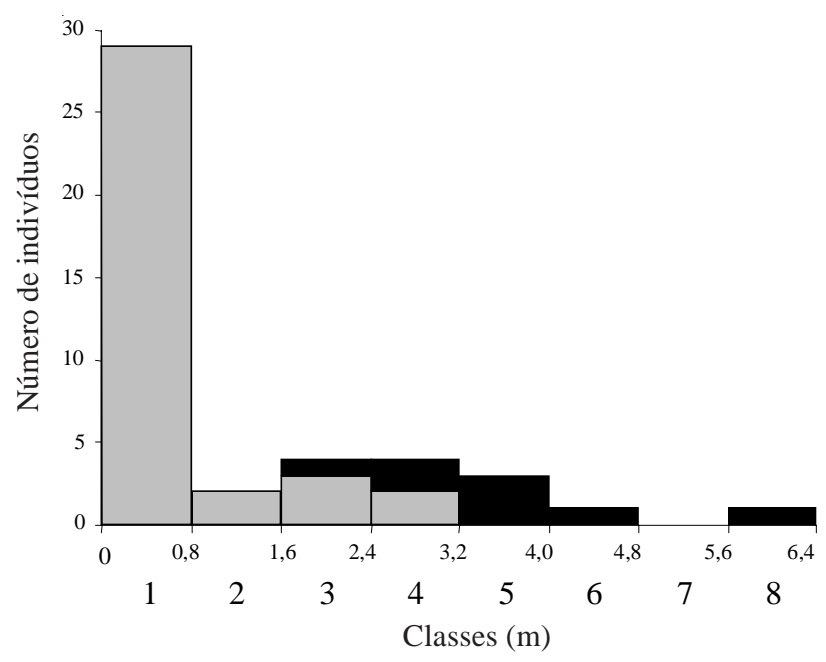

Figura 1. Distribuição de indivíduos jovens e adultos de Cyathea delgadii Sternb. por classes de altura, em uma formação florestal secundária do sul do Brasil ( $\square$ = jovens; $\boldsymbol{\square}=$ adultos). 
indivíduos por parcela. Não foram encontrados indivíduos em 22 parcelas. A espécie apresentou padrão de distribuição espacial agregado, tanto quando avaliado pelo índice de Morisita (IM = 3,69; $\mathrm{F}^{2}=152,90$; $\mathrm{p}<0,05)$ quanto pela razão $(\mathrm{R})$ variância/média $(\mathrm{R}=4,15)$. Os indivíduos jovens apresentaram-se mais fortemente agregados também quando avaliado por ambos os índices ( $\mathrm{IM}=4,88 ; \mathrm{R}=4,52 ; \mathrm{F}^{2}=173$; $\mathrm{p}<0,05)$. Apesar dos indivíduos adultos apresentarem os valores dos índices maiores que 1,0 (IM = 2,71; $\mathrm{R}=1,28$ ), o valor de Qui-Quadrado não se mostrou significativo $\left(F^{2}=49 ; p>0,05\right)$, indicando que as plantas não apresentam um padrão de distribuição espacial significativamente diferente ao do aleatório.

Crescimento do cáudice - O cáudice das plantas apresentou uma taxa média de crescimento absoluto em altura igual a 4,65 $( \pm 8,1) \mathrm{cm} \mathrm{ano}^{-1}$, sendo $40 \mathrm{~cm}$ ano ${ }^{-1} \mathrm{o}$ valor máximo registrado. A taxa média de crescimento relativo em altura foi de $5,16 \%( \pm 6,44)$, sendo $28,57 \%$ o valor máximo registrado. Durante o período estudado, 16 plantas não apresentaram incremento em sua altura. $\mathrm{O}$ crescimento absoluto do cáudice correlacionou-se fortemente $\left(\mathrm{r}_{\mathrm{s}}=0,7, \mathrm{p}<0,001\right.$, $\mathrm{n}=41$ ) com a altura. Contudo, não houve correlação entre crescimento relativo do cáudice e altura $\left(\mathrm{r}_{\mathrm{s}}=0,27\right.$, $\mathrm{p}=0,9, \mathrm{n}=41$ ) das plantas.

Fenologia da fronde - O comprimento total máximo de fronde registrado foi de $345 \mathrm{~cm}$. A maior lâmina e o maior estípite apresentaram, respectivamente, $232 \mathrm{~cm}$ e $113 \mathrm{~cm}$ de comprimento (Tab. 1). A altura do cáudice apresentou correlação com comprimento do estípite $\left(r_{s}=0,72, p<0,001, n=36\right)$, comprimento da lâmina $\left(\mathrm{r}_{\mathrm{s}}=0,84, \mathrm{p}<0,001, \mathrm{n}=36\right)$ e comprimento total da fronde $\left(r_{s}=0,8, p<0,001, n=36\right)$.

As plantas, em média, produziram $5,75( \pm 5,28)$ frondes novas por ano. No máximo, foram produzidas 23 frondes por planta. Durante todo o ano houve produção de frondes, porém esta foi irregular, sendo que nos meses de janeiro, junho, setembro e outubro foram registradas as maiores médias mensais e em

Tabela 1. Dimensões das frondes de Cyathea delgadii Sternb. em uma formação florestal secundária do sul do Brasil. $\mathrm{n}$ = número de frondes.

\begin{tabular}{lcccrc}
\hline Comprimento (cm) & $\mathrm{n}$ & Mínimo & Máximo & Média & DP \\
\hline Estípite & 36 & 12 & 113 & 59,58 & 30,04 \\
Lâmina & 36 & 19 & 232 & 104,77 & 56,65 \\
Total & 36 & 31 & 345 & 164,36 & 85,34 \\
\hline
\end{tabular}

novembro a menor média (Fig. 2). Observações adicionais indicaram que $68 \%$ das plantas apresentaram danos causados por herbivoria em frondes, geralmente, recém-expandidas. Porém, não se observou perda total de frondes ou de indivíduos da população, pela ação dos herbívoros. Aumentos na produção de frondes não se relacionaram com meses de altas precipitações $\left(r_{s}=-0,32, p=0,31\right)$, sendo que, geralmente, foram posteriores aos meses mais chuvosos (Fig. 2). A altura das plantas apresentou forte correlação $\left(r_{s}=0,76\right.$, $\mathrm{p}<0,001, \mathrm{n}=41$ ) com produção anual de frondes.

As plantas, em média, apresentaram 4,92 $( \pm 4,84)$ frondes senescentes por ano, sendo que no mês de outubro foi registrada a média máxima de $0,58( \pm 0,92)$ e em junho a média mínima de $0,21( \pm 0,47)$. Durante todos os meses do ano foram observadas plantas com senescência foliar (Fig. 2). As médias de frondes senescentes variaram menos em relação à de frondes novas, mas também não demonstraram correlação com a pluviosidade $\left(\mathrm{r}_{\mathrm{s}}=0,14, \mathrm{p}=0,67\right)$. Durante um ano, foram registradas no mínimo uma e no máximo 20

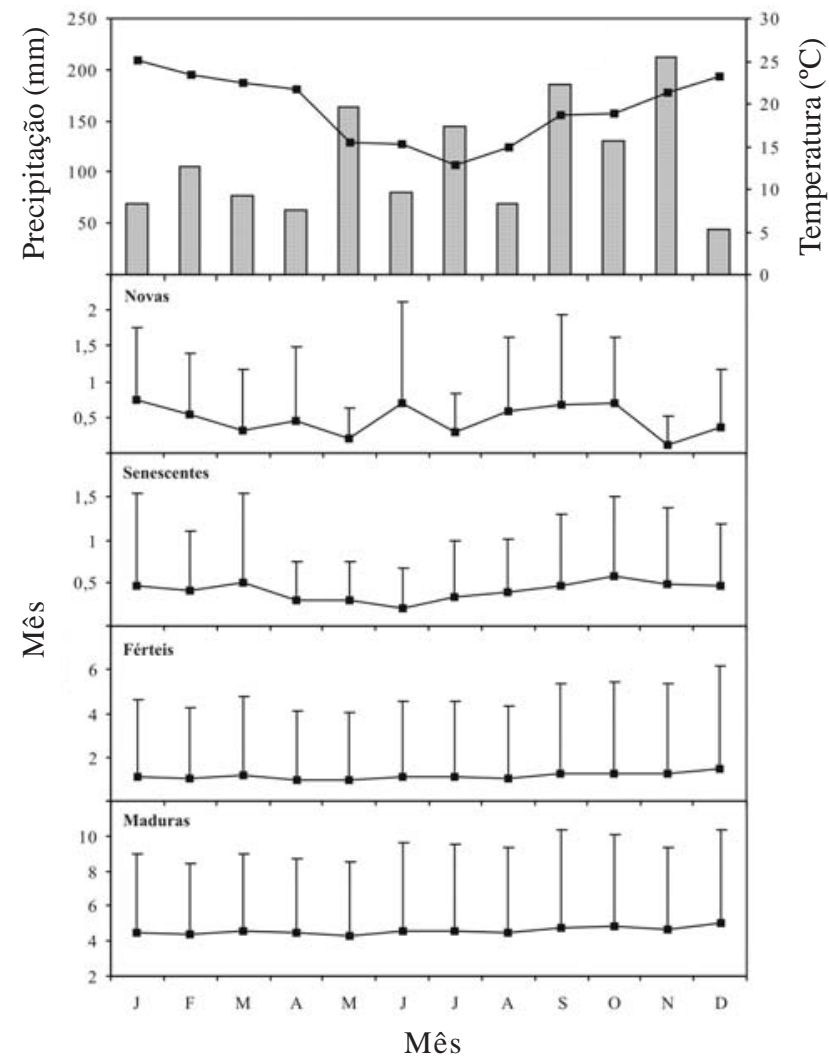

Figura 2. Temperatura média mensal, precipitação mensal acumulada e média mensal de frondes novas, senescentes, férteis e maduras de Cyathea delgadii Sternb. durante o ano de 2004, em uma formação florestal secundária do sul do Brasil. As barras indicam o desvio-padrão ( $\square=$ precipitação; $-\square-=$ temperatura $)$. 
frondes senescentes por planta. A senescência anual de frondes apresentou forte correlação $\left(r_{s}=0,8\right.$, $\mathrm{p}<0,001, \mathrm{n}=41)$ com a altura das plantas.

Durante o ano, as médias de frondes maduras e férteis foi praticamente constante (Fig. 2). A média mensal de frondes maduras $\left(\mathrm{r}_{\mathrm{s}}=0,07, \mathrm{p}=0,83\right)$ e de frondes férteis $\left(r_{s}=0,18, p=0,58\right)$ não estiveram correlacionadas com a temperatura. O número mínimo e máximo de frondes maduras por esporófito foi zero e 20, respectivamente. No mínimo e no máximo foram registradas zero e 19 frondes férteis por planta. Comparando-se a média de frondes maduras de janeiro/2004 com a de janeiro/2005, foi constatado, estatisticamente, que são iguais $(\mathrm{p}=0,421, \mathrm{n}=41)$.

Os 20 báculos marcados de Cyathea delgadii se expandiram em média $3,13( \pm 1,39) \mathrm{cm} \mathrm{dia}^{-1}$ no primeiro mês (no máximo $\left.6,71 \mathrm{~cm} \mathrm{dia}^{-1}\right), 1,14( \pm 1,05) \mathrm{cm} \mathrm{dia}^{-1}$ no segundo mês, $0,14( \pm 0,42) \mathrm{cm} \cdot$ dia $^{-1}$ no terceiro mês e $0,005( \pm 0,016) \mathrm{cm} \mathrm{dia}^{-1}$ no quarto mês. Considerando o total de báculos das plantas monitoradas, apenas seis se apresentaram necrosados, nos meses de abril (2), maio (1), novembro (1) e dezembro (2). O frio ou calor excessivo podem ter sido as principais causas de necrose dos báculos.

Apenas 9,75\% das plantas marcadas produziram frondes férteis, sendo que as mesmas no mínimo apresentavam 1,65 m de altura. Foram encontradas plantas com esporângios imaturos durante todo o ano, com exceção de janeiro, abril e maio; com esporângios cerrados de janeiro a abril e de setembro a dezembro; liberando esporos de janeiro a julho e de outubro a dezembro (Fig. 3). A maioria dos esporos foi produzida do final do inverno até o início do verão (agosto a janeiro), sendo que pelo menos $50 \%$ das plantas férteis apresentaram esporângios imaturos. A grande maioria dos esporos foi liberada a partir do verão até o início do inverno (janeiro a junho), período em que $100 \%$ das plantas férteis apresentaram frondes com esporângios abertos. Foi assincrônica a liberação de esporos em uma mesma planta, sendo que parte dos esporângios liberou seus esporos, enquanto a outra permaneceu imatura ou cerrada. De uma maneira geral, o período de maturação dos esporos foi de 60 dias, sendo que os esporângios maduros permaneceram cerrados até aproximadamente 120 dias, antes de iniciar a liberação dos esporos.

\section{Discussão}

A população de Cyathea delgadii apresentou uma distribuição de indivíduos nas classes de tamanho

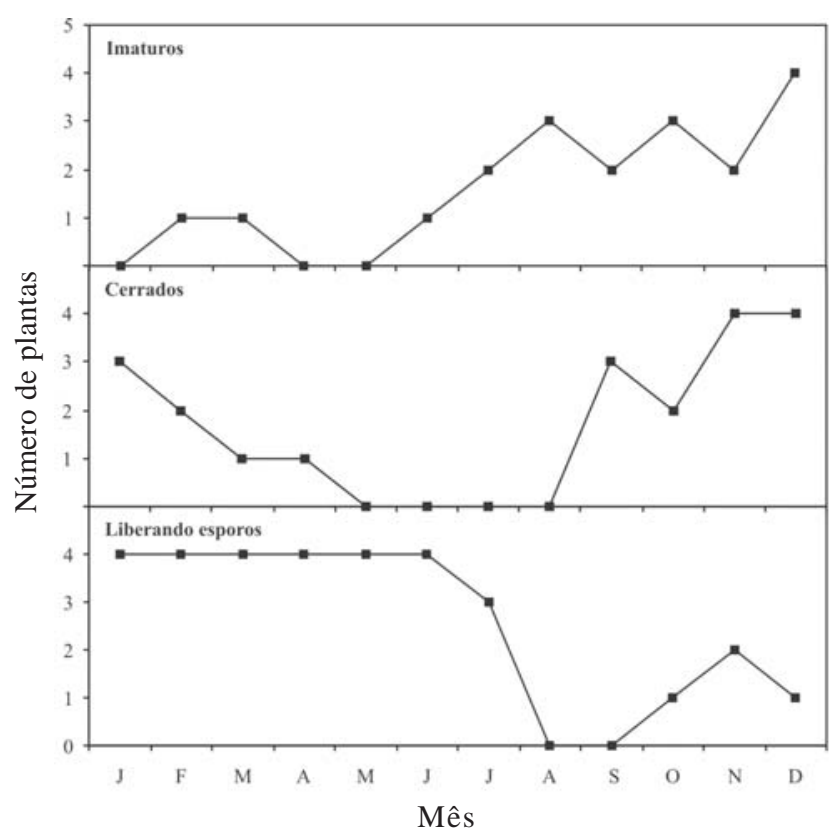

Figura 3. Número mensal de indivíduos de Cyathea delgadii Sternb. apresentando frondes com esporângios imaturos, cerrados e liberando esporos, durante o ano de 2004, em uma formação florestal secundária do sul do Brasil.

caracterizado por uma freqüência expressivamente superior nas classes de menor altura e uma freqüência menor nas classes de maior altura. Essa distribuição indica que a população está estável e crescente (Condit et al. 1998), bem como um grande potencial de recomposição, através da regeneração natural da vegetação. Resultados similares de distribuição em classes de altura de samambaias arborescentes neotropicais foram obtidos por Tanner (1983) para Cyathea pubescens Mett. ex Kuhn, na Jamaica; Ortega (1984) para uma população de Sphaeropteris senilis (Klotzsch) R.M. Tryon, na Venezuela; Seiler (1984) para Alsophila tryoniana (Gastony) D.S. Conant (= Nephelea tryoniana Gastony), em El Salvador; Young \& León $(1989 ; 1991)$ e Poulsen \& Nielsen (1995) para C. lasiosora (Mett. ex Kuhn) Domin (= Trichipteris nigra (Mart.) R.M. Tryon), no Peru e Equador, respectivamente; Nicholson (1997) para A. cuspidata (Kunze) D.S. Conant (=N. cuspidata (Kunze) R.M. Tryon) e Trichipteris sp. associada a Cyathea sp., no Peru. No sul do Brasil, Schmitt \& Windisch (2005) encontraram o mesmo modelo de distribuição para $A$. setosa Kaulf.

$\mathrm{O}$ grande número de indivíduos jovens pode estar relacionado com a presença de sítios adequados para o estabelecimento de novas plantas de Cyathea delgadii. Nesse sentido, as condições edáficas e topográficas favoráveis foram citadas por Poulsen \& 
Nielsen (1995) como fatores importantes para um elevado número de indivíduos jovens de $C$. lasiosora. Ash (1986) comentou que uma população de samambaias arborescentes com poucas plantas jovens pode ser decorrente da escassez de sítios favoráveis para o estabelecimento de novos esporófitos a partir de gametófitos. Por outro lado, muitas plantas jovens na população podem representar uma estratégia para compensar a alta mortalidade ou supressão no crescimento, evidenciada pelo número reduzido de plantas que conseguem alcançar a maturidade (Young \& León 1989). De fato, no presente estudo, 16 espécimes não apresentaram um incremento na altura do cáudice, além de um número reduzido de plantas adultas (férteis), embora não tenha sido observada morte de indivíduos, durante o período de um ano.

O grande número de parcelas sem plantas de Cyathea delgadii demonstrou a tendência da espécie de formar agrupamentos, em nichos com condições adequadas e espaçados dentro da formação florestal. A forte agregação observada nos indivíduos jovens de C. delgadii ocorreu em uma área que se encontra em estágio sucessional mais recente (observação pessoal), onde a disponibilidade de luz é maior no sub-bosque. Tal observação pode estar relacionada com o fato de que os esporos de $C$. delgadii são fotoblásticos (Randi \& Felippe 1988a; c), sendo a luminosidade um fator importante para a germinação de esporos e posterior estabelecimento de esporófitos jovens.

A partir da comparação da taxa de crescimento do cáudice de Cyathea delgadii com aquelas apresentadas por outros autores (Tab. 2), fica evidenciado que as mesmas são influenciadas pelo hábitat. Existe uma grande variação intraespecífica no crescimento dessa espécie, sendo que nos trópicos C. delgadii cresce três vezes mais em floresta secundária de que em floresta primária (Bittner \& Breckle 1995). Por outro lado, o crescimento registrado dessas plantas, no presente estudo, em floresta secundária subtropical, de baixa altitude, com menor precipitação anual foi expressivamente menor daqueles indicados por Bittner \& Breckle (1995). Além disso, a comparação também demonstrou que há uma grande variação interespecífica entre as espécies de Cyathea (Arens 2001), sendo que populações de latitudes mais austrais apresentaram as menores taxas de crescimento. Em climas tropicais e subtropicais, sabe-se que pequenas variações de temperatura e chuvas intensas interferem no crescimento ou em outros processos de desenvolvimento das plantas arborescentes (Larcher 2000). Além disso, as diferenças nas taxas de crescimento de $C$. delgadii em diferentes sítios, sugerem que diferenças no dossel e nos estágios de sucessão das formações florestais, bem como incidência de luz e competição influenciam o crescimento da espécie. Nesse sentido, Arens (2001) apresentou dados sobre diferenças no crescimento do cáudice de C. caracasana (Klotzsch) Domin, em locais com diferentes estágios de sucessão, indicando que em formações florestais secundárias mais antigas as plantas crescem menos em altura. Finalmente, as variações intraespecíficas observadas no crescimento do cáudice de $C$. delgadii podem estar relacionadas com diferenças na estrutura das populações, visto que este se correlaciona fortemente com a altura das plantas.

Os esporófitos de Cyathea delgadii de maior altura apresentaram frondes com estípite de maior comprimento, contrariando o registrado por Seiler (1984) para Alsophila tryoniana e por Schmitt \& Windisch (2003) para A. setosa. Por outro lado, Arens \& Sánchez Baracaldo (2000) não encontraram correlações significativas entre altura do cáudice e comprimento do estípite para $C$. caracasana. A ocorrência de boas correlações entre o comprimento da lâmina e total das frondes com a altura das plantas de $C$. delgadii, sugerem que as diferenças no tamanho foliar estão relacionadas com classes de tamanho-idade

Tabela 2. Comparação de taxas de crescimento do cáudice de Cyathea delgadii Sternb. com outras espécies do gênero.

\begin{tabular}{|c|c|c|c|c|c|}
\hline Espécie & $\mathrm{TC}\left(\mathrm{cm} \mathrm{ano} \mathrm{s}^{-1}\right)$ & Floresta & Coordenadas geográficas & Altitude (m) & Precipitação (mm) \\
\hline Cyathea trichiata & $89,70^{\mathrm{a}}$ & secundária & $10^{\circ} 12^{\prime} \mathrm{N} ; 8^{\circ} 36^{\prime} \mathrm{W}$ & $850-1.150$ & 3.300 \\
\hline Cyathea delgadii & $81,90^{\text {a }}$ & secundária & $10^{\circ} 12^{\prime} \mathrm{N} ; 8^{\circ} 36^{\prime} \mathrm{W}$ & $850-1.150$ & 3.300 \\
\hline Cyathea delgadii & $21,30^{\mathrm{a}}$ & primária & $10^{\circ} 12^{\prime} \mathrm{N} ; 84^{\circ} 36^{\prime} \mathrm{W}$ & $850-1.150$ & 3.300 \\
\hline Cyathea caracasana & $16,80 * \mathrm{~b}$ & secundária & $01^{\circ} 09^{\prime} \mathrm{N} ; 7^{\circ} 59^{\prime} \mathrm{W}$ & $1.850-2.300$ & 4.500 \\
\hline Cyathea delgadii & $4,65^{\mathrm{c}}$ & secundária & $29^{\circ} 43^{\prime} \mathrm{S} ; 50^{\circ} 58^{\prime} \mathrm{W}$ & 47 & $1.341,6$ \\
\hline Cyathea atrovirens & $2,48^{\mathrm{d}}$ & secundária & $29^{\circ} 41^{\prime} \mathrm{S} ; 51^{\circ} 06^{\prime} \mathrm{W}$ & 16,4 & $1.341,6$ \\
\hline
\end{tabular}

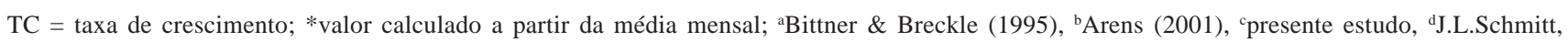
dados não publicados. 
dos cáudices. Por razões mecânicas, as frondes podem ser maiores, em plantas mais altas, porque os cáudices, mais desenvolvidos, especialmente de maior diâmetro, podem suportar maior massa foliar. Seiler (1984) verificou uma correlação regular entre altura do cáudice e comprimento da lâmina para A. tryoniana, bem como Arens \& Sánchez Baracaldo (2000) para C. caracasana. Estudos adicionais são necessários para determinar quais fatores ambientais e de desenvolvimento interno são preponderantes para explicar as correlações encontradas entre altura e dimensões das frondes. A idade do meristema apical (Seiler 1984) e, principalmente, a intensidade e a qualidade de luz (Seiler 1984; Arens \& Sánchez Baracaldo 2000) influenciam o desenvolvimento das frondes em ciateáceas.

A tendência de aumento de produção de frondes em indivíduos de Cyathea delgadii de maior altura também foi verificada por Tanner (1983) para esporófitos de $C$. pubescens, na Jamaica e por Schmitt \& Windisch (2003) para Alsophila setosa, no sul do Brasil. A forte correlação entre produção foliar e altura das plantas reforça a hipótese de que o desenvolvimento das frondes de $C$. delgadii esteja relacionado com tamanho-idade dos cáudices, bem como a fatores ambientais, entre os quais destaca-se a luz. Possivelmente, as plantas mais altas interceptam mais luz no sub-bosque, aumentando sua produtividade e desenvolvendo mais frondes. Seiler (1981) verificou que a produção de frondes foi constante para a altura de A. salvinii, crescendo em áreas totalmente iluminadas, em formação florestal secundária de El Salvador.

A produção de novas frondes de Cyathea delgadii foi assincrônica e similar ao observado em C. pubescens (Tanner 1983), C. hornei (Baker) Copel. (Ash 1987) e C. caracasana (Arens 2001). A assincronia na produção de frondes não é típica de todas as samambaias arborescentes neotropicais, sendo que as frondes de Dicksonia sellowiana Hook. (Hoehne 1930) e Alsophila setosa (Schmitt \& Windisch 2001) desenrolam-se, sincronicamente, na primavera. Similarmente ao observado em $C$. caracasana (Arens 2001) e Cibotium spp. (Wick \& Hashimoto 1971; Durand \& Goldstein 2001), a produção de frondes em $C$. delgadii não apresentou correlação com precipitação, possivelmente porque não ocorreu um período de intensa deficiência hídrica que pudesse limitar a produção foliar, além de que o clima na região estudada é úmido o ano inteiro. Um significado ecológico importante da produção de frondes em múltiplos meses é a redução do perigo representado pela herbivoria ou pelo parasitismo acentuado, os quais poderiam causar uma perda total da folhagem (Larcher 2000), em um período em que o clima favorece a reprodução de herbívoros ou parasitas.

A senescência foliar de Cyathea delgadii foi assincrônica, demonstrando não estar necessariamente correlacionada com pluviosidade. A assincronia na senescência foliar também foi observada em C. pubescens (Tanner 1983), C. hornei (Ash 1987), Cibotium glaucum (Sm.) Hook. \& Arn. (Walker \& Aplet 1994) e Alsophila salvinii (Seiler 1981). Similarmente ao registrado para $C$. delgadii, a senescência das frondes também foi menos sazonal para C. hornei (Ash 1987). Ao contrário, A. salvinii (Seiler 1981) apresentou sazonalidade na senescência foliar, sendo que poucas frondes morrem de janeiro a junho. De modo geral, as plantas mais altas de C. delgadii apresentaram maior número de frondes senescentes provavelmente devido ao fato de que indivíduos mais altos apresentam um maior número de frondes (em decorrência de maiores taxas de produção foliar) expostas às condições de ressecamento de que as plantas menores.

Similarmente ao registrado no presente estudo, Bittner \& Breckle (1995) registraram uma regularidade nas médias de frondes maduras, durante um ano inteiro, em Cyathea delgadii e C. trichiata (Maxon) Domin, crescendo em floresta secundária. Taxas anuais de produção foliar e de senescência iguais evidenciaram uma capacidade de $C$. delgadii manter o número de frondes, a cada ano. Da mesma forma $C$. hornei (Ash 1987), Alsophila setosa (Schmitt \& Windisch 2001), Sphaeropteris senilis (Ortega 1984) apresentam capacidade de recuperar praticamente todas as frondes perdidas, mantendo o número de frondes maduras relativamente estável, a cada ciclo.

A ausência de correlação entre desenvolvimento das frondes, precipitação e temperatura, aparentemente refletiu na assincronia observada na produção e senescência foliar, bem como na regularidade do número de frondes maduras e férteis na população. Possivelmente, o dossel contínuo, serviu de proteção contra o frio, geadas e incidência da radiação excessiva, bem como o córrego manteve a umidade local, resultando em condições ambientais mais uniformes, no sub-bosque, contribuindo para a manutenção do número de frondes das plantas, no decorrer do ano.

A expansão das frondes muito rápida durante a maturação e, posteriormente, muito mais lenta 
observada para Cyathea delgadii também foi registrada para $C$. pubescens. Porém, essa última espécie apresentou valor máximo de expansão igual a $4,94 \mathrm{~cm} \mathrm{dia}^{-1}$ (Shreve 1914), o que é inferior ao observado em $C$. delgadii $\left(6,71 \mathrm{~cm} \mathrm{dia}^{-1}\right)$. Os báculos de $C$. delgadii são resistentes às variações de temperatura e de precipitação, bem como à incidência de geadas, visto que o número de báculos necrosados foi extremamente reduzido, durante o ano inteiro. Dentre os fatores que exercem proteção dos báculos pode-se destacar: o efeito tamponante do dossel no sub-bosque, amenizando as variações climáticas e protegendo quanto à ação de geadas; a cobertura de escamas castanho-claras ou ferrugíneas sobre o meristema apical; e, em plantas mais altas, com coroa de frondes maior, a matéria orgânica depositada na porção apical do cáudice, constituída basicamente de restos vegetais. As escamas protegem o meristema apical e podem absorver água da umidade atmosférica ou da chuva, hidratando as frondes já expandidas (Barrington 1978; Tryon \& Tryon 1982).

Um dos fatores limitantes da produção de frondes férteis de Cyathea delgadii foi a freqüência de indivíduos que chegaram na idade reprodutiva, uma vez que as classes de menor altura foram as mais numerosas. O mesmo fato foi observado para C. lasiosora (Young \& León 1989) e Alsophila setosa (Rosenstock 1907; Schmitt \& Windisch 2005), porém não é regra geral para todas as ciateáceas, uma vez que espécimes de $C$. atrovirens, com $10 \mathrm{~cm}$ de altura, podem começar a sua produção de esporos (J.L.S., dados não publicados). Randii \& Felippe (1988a) comentaram que a produção de esporos de C. delgadii ocorre o ano inteiro, similarmente ao registrado no presente estudo. Além disso, Ortega (1984) também observou que aparentemente a presença de frondes férteis em Sphaeropteris senilis não tem nenhuma relação com mudanças climáticas. A assincronia na produção e liberação de esporos evita que toda a produção seja perdida, em um período desfavorável, permite o aproveitamento de mais microhabitats recém expostos (Ranal 1995) e pode compensar o baixo número de indivíduos férteis, na população de C. delgadii.

\section{Agradecimentos}

Ao Programa de Pós-Graduação em Botânica da Universidade Federal do Rio Grande do Sul - UFRGS, pela oportunidade de realização deste estudo; ao Centro Universitário FEEVALE, pela concessão de bolsa auxílio-doutorado; à Sra. Zalir Emília de Lima e à Sra. Janete Teresinha da Conceição por autorizarem o trabalho de campo no Turiscampo; ao Nilson Wolff, pelo fornecimento dos dados climatológicos; ao Ismael Franz, à Cristina L.J. Schmitt, demais familiares e alunos do curso de Ciências Biológicas da FEEVALE, pelo auxílio prestado e estímulos para a realização do presente trabalho.

\section{Referências bibliográficas}

Arens, N.C. 2001. Variation in performance of the tree fern Cyathea caracasana (Cyatheaceae) across a sucessional mosaic in Andean cloud forest. American Journal of Botany 88: 545-551.

Arens, N.C. \& Sánchez Baracaldo, P. 1998. Distribution of tree ferns (Cyatheaceae) across a sucessional mosaic in an Andean cloud forest, Nariño, Colombia. American Fern Journal 88: 60-71.

Arens, N.C. \& Sánchez Baracaldo, P. 2000. Variation in tree fern stipe length with canopy height: tracking preferred habitat through morphological change. American Fern Journal 90: 1-15.

Arens, N.C. \& Smith, A.R. 1998. Cyathea planadae, a remarkable new creeping tree fern from Colombia, South America. American Fern Journal 88: 49-59.

Ash, J. 1986. Demography and production of Leptopteris wilkesiana (Osmundaceae), a tropical tree-fern from Fiji. Australian Journal of Botany 34: 207-215.

Ash, J. 1987. Demography of Cyathea hornei (Cyatheaceae), a tropical tree-fern in Fiji. Australian Journal of Botany 35: 331-342.

Barrington, D.S. 1978. A revision of the genus Trichipteris. Contributions from the Gray Herbarium of Harvard University 208: 3-91.

Bittner, J. \& Breckle, S.W. 1995. The growth rate and age of tree fern trunks in relation to habitats. American Fern Journal 85: 37-42.

Conant, D.S. 1976. Ecogeographic and systematic studies in American Cyatheaceae. Ph.D. Thesis, Harvard University, Cambridge, Mass.

Condit, R.; Sukumar, R.; Hubbell, S.P. \& Foster, R.B. 1998. Predicting population trends from size distributions: a direct test in a tropical tree community. The American Naturalist 152: 495-509.

Corrêa, M.P. 1984. Dicionário das plantas úteis do Brasil e das exóticas cultivadas. $2^{a}$ ed. Instituto Brasileiro de Desenvolvimento Florestal.

Durand, L.Z. \& Goldstein, G. 2001. Growth, leaf characteristics, and spore production in native and invasive tree ferns in Hawaii. American Fern Journal 91: 25-35.

Fernandes, I. 2003. Taxonomia dos representantes de Cyatheaceae do nordeste oriental do Brasil. Pesquisas, Botânica 53: 7-53.

Gomez, L.D. 1983. Cyatheaceae \& Dicksoniaceae (Rabos de Mico, Tree Ferns). Pp. 225-226. In: D.H. Janzen (ed.). Costa Rican Natural History. Chicago, University of Chicago Press. 
Hoehne, F.C. 1930. As plantas ornamentaes da flora brasílica e o seu papel como factores da salubridade publica, da esthética urbana e artes decorativas nacionaes. Separata do Boletim de Agricultura, Secretaria da Agricultura, Indústria e Comércio do Estado de São Paulo: 115-130.

Holttum, R.E. \& Edwards, P.J. 1983. The tree-ferns of Mount Roraima and neighbouring areas of the Guayana highlands with comments on the family Cyatheaceae. Kew Bulletin 38: 155-188.

Klein, R.M. 1979. Ecologia da flora e vegetação do Vale do Itajaí. Sellowia 31: 11-164.

Krebs, C.J. 1989. Ecological Methodology. New York, Harper Collins.

Larcher, W. 2000. Ecofisiologia vegetal. São Carlos, Rima Artes e Textos.

Lorscheitter, M.L.; Ashraf, A.R.; Windsch, P.G. \& Mosbrugger, V. 1999. Sonder-Abdruck aus Palaeontographica Beiträge zur Naturgeschichte der Vorzeit. PartII. Pteridophyte spores of Rio Grande do Sul flora, Brazil. Stuttgart, E. schweizerbart'sche Verlagsbuchhandlung.

Marcondes-Ferreira, W. \& Felippe, G.M. 1984. Effects of light and temperature on the germination of spores of Cyathea delgadii. Revista Brasileira de Botânica 7: 53-56.

Moreno, J.A. 1961. Clima do Rio Grande do Sul. Porto Alegre, Secretaria da Agricultura.

Nicholson, B. 1997. Obervations on the distribution and diversity of tree ferns in the Zona Reservada de Tambopata, Madre Rios, Peru. Fern Gazette 15: 153-159.

Ortega, F. 1984. Notas sobre la autoecología de Sphaeropteris senilis (KL) Tryon (Cyatheaceae) en el Parque Nacional el Avila - Venezuela. Pittieria 12: 31-53.

Poulsen, A.D. \& Nielsen, I.H. 1995. How many ferns are there in one hectare of tropical rain forest? American Fern Journal 85: 29-35.

Ranal, M.A. 1995. Estabelecimento de pteridófitas em mata mesófila semidecídua do Estado de São Paulo. 3. Fenologia e sobrevivência dos indivíduos. Revista Brasileira de Biologia 55: 777-787.

Randi, A.M. \& Crozier, A. 1991. Gibberellins, indole3-acetic acid and the germination of spores of the tree fern Cyathea delgadii Sternb. Revista Brasileira de Botânica 14: 67-72.

Randi, A.M. \& Felippe, G.M. 1988a. Efeito do armazenamento de esporos, da aplicação de DCMU e da pré-embebição em PEG na germinação de Cyathea delgadii. Ciência e Cultura 40: 484-489.

Randi, A.M. \& Felippe, G.M. 1988b. Lipid content during germination of spores of the fern Cyathea delgadii. Revista Brasileira de Botânica 11: 37-39.

Randi, A.M. \& Felippe, G.M. 1988c. Effect of red light and far-red on the germination of spores of Cyathea delgadii. Revista Brasileira de Botânica 11: 41-45.

Randi, A.M. \& Felippe, G.M. 1988d. Germinação de esporos de Cyathea delgadii sob luz azul e aplicações longas de vermelho. Revista Brasileira de Biologia 48: 979-984.
Randi, A. M. \& Felippe, G. M. 1988e. Efeito da préembebição em atmosfera úmida na fotossensibilidade de esporos de Cyathea delgadii Sternb. Hoehnea 15: 20-27.

Randi, A.M. \& Felippe, G.M. 1988f. Efeitos da temperatura durante a pré e a pós-indução e do período de armazenamento na germinação de esporos de Cyathea delgadii Sternb. Hoehnea 15: 10-19.

Rosenstock, E. 1907. Beiträge zur pteridophytenflora Südbrasiliens. II. Hedwigia 46: 57-69.

Schmitt, J.L. \& Windisch, P.G. 2001. Prejuízos causados pela geada no desenvolvimento de Alsophila setosa Kaulf. (Pteridophyta, Cyatheaceae). Revista de estudos / Centro Universitário Feevale 24: 79-88.

Schmitt, J.L. \& Windisch, P.G. 2003. Relação entre comprimento do estípite, produção de frondes e tamanho do cáudice, em Alsophila setosa Kaulf. (Pteridophyta, Cyatheaceae). Pesquisas Botânica 53: 55-63.

Schmitt, J.L. \& Windisch, P.G. 2005. Aspectos ecológicos de Alsophila setosa Kaulf. (Cyatheaceae, Pteridophyta) no sul do Brasil. Acta Botanica Brasilica 19: 861-867.

Schmitt, J.L. \& Windisch, P.G. 2006. Phenological aspects of frond production in Alsophila setosa Kaulf. (Cyatheaceae: Pteridophyta) in southern Brazil. Fern Gazette 17: 263-270.

Seiler, R.L. 1981. Leaf turnover rates and natural history of the Central American tree fern Alsophila salvinii. American Fern Journal 71: 75-81.

Seiler, R.L. 1984. Trunk length and frond size in a population of Nephelea tryoniana from El Salvador. American Fern Journal 74: 105-107.

Shreve, F. 1914. A Montane Rain-Forest: A contribution to the physiological plant geography of Jamaica. Washington D.C., Carnegie Institution of Washington.

Sylvestre, L.S. \& Kurtz, B.C. 1994. Cyatheaceae. Pp. 139-152. In: Lima, M.P.M. \& Guedes-Bruni, R.R. (orgs.). Reserva Ecológica de Macaé de Cima, Nova Friburgo-RJ. Aspectos florísticos das espécies vasculares. v.1. Rio de Janeiro, Ministério do Meio Ambiente e da Amazônia Legal/IBAMA/Jardim Botânico do Rio de Janeiro.

Tanner, E.V.J. 1983. Leaf demography and growth of treefern Cyathea pubescens Mett. Ex Kuhn in Jamaica. Botanical Journal of the Linnean Society 87: 213-227.

Teixeira, M.B.; Coura Neto, A.B.; Pastore, U. \& Rangel Filho, A.L.R. 1986. Vegetação. Pp. 541-620. In: Levantamento de recursos naturais. v.33. Rio de Janeiro, IBGE.

Tryon, R. 1976. A revision of the genus Cyathea. Contributions from the Gray Herbarium of Harvard University 206: 19-101.

Tryon, R. \& Tryon, A. 1982. Ferns and allied plants with special reference to Tropical America. New York, Springer Verlag.

Vieira, S. 1980. Introdução à Bioestatística. 3. ed. Rio de Janeiro, Campus.

Walker, L.R. \& Aplet, G.H. 1994. Growth and fertilization responses of Hawaiian tree ferns. Biotropica 26: 378-383. 
740 Schmitt \& Windisch: Estrutura populacional e desenvolvimento da fase esporofítica de Cyathea delgadii Sternb. ...

Wick, H.L. \& Hashimoto, G.T. 1971. Leaf development and stem growth of treefern in Hawaii. U.S. For. Serv. Res. Note PSW-237, Pacific Southwest For. and Range Expt. Sta., Berkeley, California.

Young, K.R. \& León, B. 1989. Pteridophyte species diversity the Central Peruvian Amazon: importance of edaphic specialization. Brittonia 41: 388-395.
Young, K.R. \& León, B. 1991. Diversity ecology and distribution of high-elevation pteridophytes within Abiseo National Park, north-central Peru. Fern Gazette 14: 25-39.

Zar, J.H. 1999. Bioestatistical analysis. 4. ed. Upper Saddle River, Prentice-Hall. 